Brief Report

\title{
Frequency Response Improvement of PMSG Wind Turbines Using a Washout Filter
}

\author{
Parisa M. Shabestari ${ }^{1}$ and Ali Mehrizi-Sani ${ }^{2, *} \mathbb{D}$ \\ 1 School of Electrical Engineering and Computer Science, Washington State University, \\ Pullman, WA 99164, USA; parisa.m.shabestari@wsu.edu \\ 2 Bradley Department of Electrical and Computer Engineering, Virginia Tech, Blacksburg, VA 24061, USA \\ * Correspondence: mehrizi@vt.edu
}

Received: 21 August 2020; Accepted: 9 September 2020; Published: 14 September 2020

\begin{abstract}
High integration of renewable energy resources, such as wind turbines, to the power grid decreases the power system inertia. To improve the frequency response of a low-inertia system, virtual inertia approach can be used. This letter proposes a control method to decrease the frequency transients and restore frequency to its nominal value. A wind turbine usually works based on maximum power point tracking (MPPT) curves to achieve the maximum power. In this letter, the proposed controller uses a non-MPPT method to leave power for frequency regulation during transients. Moreover, it uses a washout filter-based method to remove the steady-state error in the frequency. Simulation results in the PSCAD environment validate the improved performance of the proposed method during load changes by comparing it with the MPPT and non-MPPT methods.
\end{abstract}

Keywords: control; frequency regulation; inertia support; PMSG wind turbine; washout filter

\section{Introduction}

Due to the increased number of wind turbines in the power grid $(7.28 \%$ wind energy production in the US in 2019 [1]), inertia of the grid decreases and frequency deviation and the rate of change of frequency (RoCoF) increase. This letter focuses on the inertia support of the permanent magnet synchronous generator (PMSG) wind turbines because they are used in most recent wind turbine installments. There are different sources of inertia support in PMSG wind turbines which utilize reserved energy by pitching (turning the blade angle), rotating kinetic energy, and DC link capacitor energy [2]. The pitch-based controller is slow, increases the power loss, and causes mechanical stress on turbine blades. The DC link capacitor-based controller does not provide considerable frequency support due the limited stored energy in the capacitor. The most common method in frequency regulation is using the wind turbine rotating kinetic energy. Reference [3] uses a decoupling control method to improve the frequency response during load changes. In this method, the reference power of the wind turbine can deviate from its maximum power point tracking (MPPT) value. Therefore, the wind turbine can be adjusted to provide a power lower than maximum power point (MPP) to reserve extra power for frequency regulation. However, this method does not restore the frequency to its nominal value.

This letter proposes a hybrid control method, in which the wind turbine (i) works in non-MPPT operating mode to decrease the frequency transients; and (ii) uses a washout filter-based controller to restore the frequency to the nominal value. A washout filter is a first-order high-pass filter that removes the DC component of the signal. The proposed method is simple and does not need a communication link $[4,5]$.

In this work, the conventional MPPT method is used as a base control algorithm for comparison. However, there are different MPPT methods such as optimal tip speed ratio (TSR), 
optimal relationship-based (ORB), optimal torque control (OTC), and adaptive reinforcement learning (RL) methods proposed in different research studies [6-8].

\section{PMSG Wind Turbine Operating Methods}

Figure 1 shows the schematic diagram of a back-to-back converter-based PMSG wind turbine connected to the grid; the grid is represented as a synchronous generator (SG). The machine-side converter (MSC) controls the power extraction from the wind turbine, and the grid-side converter (GSC) is responsible for injecting the generated power $\left(P_{\text {ref }}\right)$ to the grid. $P_{\text {ref }}$ can be determined based on the selected operating method such as MPPT, non-MPPT, and the proposed method in this letter.

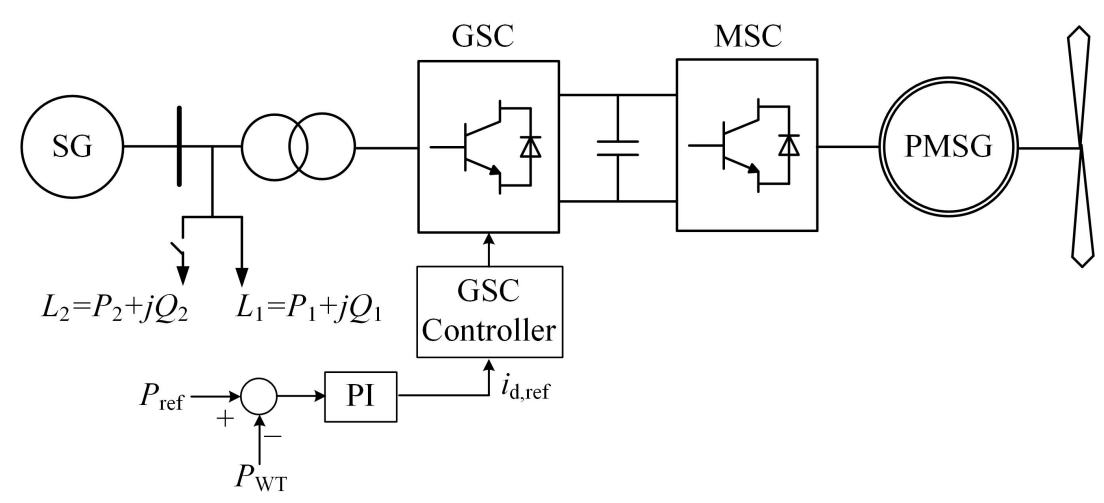

Figure 1. Schematic diagram of the PMSG wind turbine.

\subsection{MPPT Method}

The objective of the MPPT mode of operation is to extract the maximum power available to a wind turbine [9]. The reference power based on the MPPT method can be calculated as

$$
P_{\text {ref }}=P_{\mathrm{MPPT}}=\frac{1}{2} \rho \pi R^{2} C_{\mathrm{P}, \max } v^{3},
$$

where $\rho$ is the air density, $R$ is the rotor blade radius, $C_{P, \max }$ is the maximum power conversion coefficient, and $v$ is the wind speed. For a given wind speed, the optimum rotor angular speed is defined as $\omega_{\mathrm{m}, \mathrm{opt}}=\frac{v \lambda_{\mathrm{opt}}}{R}$ to extract the maximum power, where $\lambda_{\mathrm{opt}}$ is the optimum tip speed ratio. Figure 2 shows the characteristic curves of a wind turbine, which determine the wind turbine power for a given wind speed $v_{i}$ and rotor angular speed $\omega_{i}$. For each value of wind speed, there is a specific angular speed in which the maximum power can be extracted from the wind turbine. Therefore, the angular speed of the PMSG wind turbine changes by wind speed variation in the MPPT mode, and the operating point tracks the peak of each curve in Figure 2.

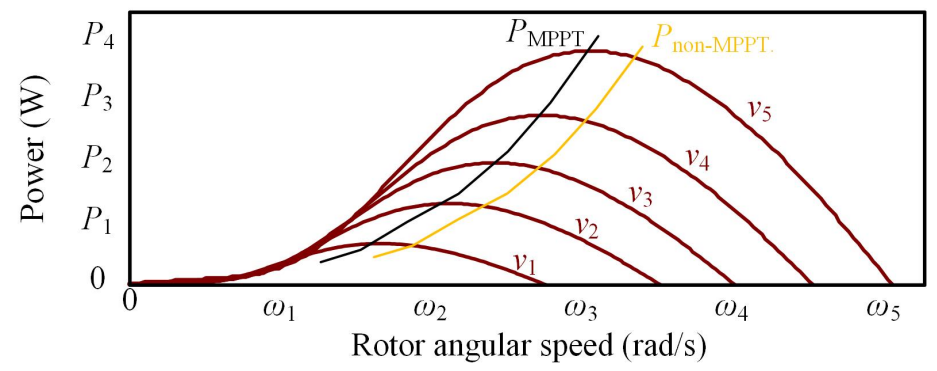

Figure 2. Characteristic curves for a wind turbine. 


\subsection{Non-MPPT Method}

In the non-MPPT method, the wind turbine generates less than its maximum available power to reserve power for frequency regulation during load variations [3]. Figure 2 shows the non-MPPT mode operating points. To prevent frequency drop during a load increase, the reserved power of the wind turbine is injected into the grid for frequency support. During a load reduction, the injected wind turbine power decreases for frequency support. The dynamic equation of the non-MPPT controller is

$$
P_{\text {ref }}=k_{p} P_{\mathrm{MPPT}}+k_{f}\left(\frac{1}{T_{g} s+1}\right)\left(f_{n}-f_{\text {grid }}\right),
$$

where $P_{\mathrm{MPPT}}$ is the chosen operating power by the MPPT method, $f_{n}$ is the grid nominal frequency, $f_{\text {grid }}$ is the grid actual frequency, $k_{p}$ is the ratio of the non-MPPT power to the MPPT power, and $k_{f}$ is the parameter of the frequency proportional controller. By tuning the value of the parameter $k_{p}$, the amount of the reserved power in the non-MPPT method can be determined. The non-MPPT method improves the transient behavior of the grid frequency and reduces its RoCoF; however, it has a steady-state error, and frequency cannot reach its nominal value. To overcome this issue, this letter proposes a hybrid non-MPPT and washout-based method.

\subsection{Proposed Method}

For the system shown in Figure 1, the conventional droop control algorithm to share power between SG and wind turbine is

$$
\Delta f+m_{p} \Delta P=0,
$$

where $\Delta f=f_{\text {grid }}-f_{n}$ and $\Delta P=P_{\mathrm{WT}}-P_{\text {ref }}\left(P_{\mathrm{WT}}\right.$ is the wind turbine output power). Equation (3) enables power sharing between the SG and wind turbine; however, it does not guarantee the restoration of frequency to its nominal value. To solve this issue, a new term $k_{w} \Delta f$ is added to the derivative of Equation (3) as Equation (4)

$$
\frac{d}{d t} \Delta f+m_{p} \frac{d}{d t} \Delta P+k_{w} \Delta f=0 .
$$

Since the derivative terms are zero in the steady state, $\Delta f$ goes to zero and the steady-state frequency restores to its nominal value. Equation (4) can be written in the Laplace domain as

$$
s \Delta f(s)+m_{p} s \Delta P(s)+k_{w} \Delta f=0 .
$$

Rewriting Equation (5) gives the following equation, which is defined as a washout filter:

$$
\Delta P(s)=\left(\frac{s+k_{w}}{m_{p} s}\right) \Delta f(s) .
$$

Using the washout filter-based controller in Equation (6), which is a dynamic feedback, rejects the DC component and passes the transient signals. The important advantage of using the washout filter is to make the system robust and maintain the frequency at its reference value during a load variation.

The proposed controller in this letter is a hybrid control method using the non-MPPT and the washout filter-based methods to reduce the frequency transients and mimic the frequency steady-state error. Figure 3 shows the block diagram of the non-MPPT controller and the proposed washout filter-based frequency support controller with the following equation:

$$
P_{\text {ref }}=k_{p} P_{\text {MPPT }}+ \begin{cases}k_{f}\left(\frac{1}{T_{g} s+1}\right)\left(f_{n}-f_{\text {grid }}\right), & \text { sw }=\mathrm{A} \\ \frac{s+k_{w}}{m_{p} s}\left(f_{n}-f_{\text {grid }}\right) . & \text { sw }=\mathrm{B}\end{cases}
$$

when the switch is connected to point $A$, the study system works with the non-MPPT controller and when the switch is connected to point $B$, it is working with the proposed control method. 


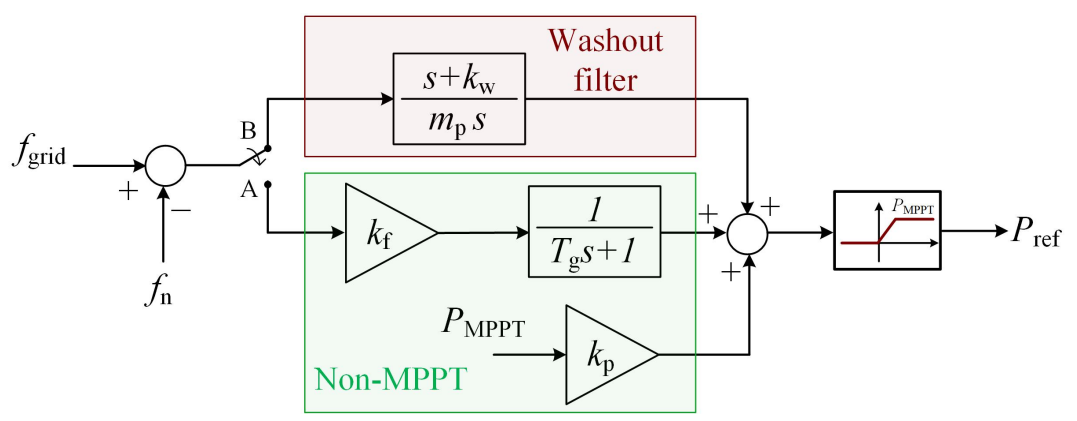

Figure 3. The proposed controller block diagram.

\section{Simulation Results}

The study system in Figure 1 with the parameters in Table 1 is simulated in PSCAD. A wind farm including 8 parallel PMSG wind turbines with a total power of $40 \mathrm{MW}$ is considered in the simulation case studies. In each wind turbine, both GSC and MSC use a conventional PI current controller. The active power controller generates the $d$-axis reference current for the inner PI current controller of the GSC. The reference active power, $P_{\text {ref }}$ in Figure 1, is determined based on the selected operating method discussed in this letter. $P_{\mathrm{MPPT}}$ is calculated based on the $C_{p}$ curves presented in [10]. To improve the transient behavior of the frequency, the wind turbine works in non-MPPT mode generating $90 \%$ of its MPPT value (i.e., $k_{\mathrm{p}}=0.9$ ). The MPPT, non-MPPT, and the proposed controllers are studied in two different scenarios.

Table 1. Parameters of the study system.

\begin{tabular}{ll}
\hline PMSG Wind Turbine Parameters & Value \\
\hline Rated power & $5 \mathrm{MW}$ \\
Number of wind turbines & 8 \\
Grid-side converter reactor & $0.25 \mathrm{pu}$ \\
Machine-side converter reactor & $0.25 \mathrm{pu}$ \\
Nominal wind speed & $11 \mathrm{~m} / \mathrm{s}$ \\
Nominal frequency & $60 \mathrm{~Hz}$ \\
Machine terminal voltage & $0.69 \mathrm{kV}$ \\
DC link capacitance & $100 \mathrm{mF}$ \\
DC link voltage & $1.45 \mathrm{kV}$ \\
\hline Load Parameters & Value \\
\hline Load 1, $L_{1}$ & $50 \mathrm{MW}+\mathrm{j} 5 \mathrm{MVAr}$ \\
Load 2, $L_{2}$ & $5 \mathrm{MW}+\mathrm{j} 0.5 \mathrm{MVAr}$ \\
\hline
\end{tabular}

\subsection{Scenario I}

In Scenario I, the initial load connected to the system is $L_{1}=P_{1}+j Q_{1}$; a second load $L_{2}=P_{2}+j Q_{2}$ is connected to the system at $t=5 \mathrm{~s}$. Figure 4 shows the simulation results for this scenario. Figure $4 \mathrm{a}$ shows the frequency drops to $58.88 \mathrm{~Hz}$ and reaches $59.88 \mathrm{~Hz}$ in the steady-state with the MPPT method (conventional controller). Using the non-MPPT method decreases the frequency drop to $59.41 \mathrm{~Hz}$ with a steady-state value of $59.88 \mathrm{~Hz}$. However, with the proposed control method the frequency drops to $59.63 \mathrm{~Hz}$, which is then restored to $60 \mathrm{~Hz}$ in the steady state. Figure $4 \mathrm{a}$ also shows that the settling time in the proposed method reduces from $100 \mathrm{~s}$ (in the MPPT method) and $85 \mathrm{~s}$ (in the non-MPPT method) to $62 \mathrm{~s}$, which show a $48 \%$ and $27 \%$ improvement, respectively. Figure $4 \mathrm{~b}$ shows that RoCoF is smaller in the proposed method than the MPPT and non-MPPT methods. It reaches from nadir to zero in $9.5 \mathrm{~s}, 5.5 \mathrm{~s}$, and $2.5 \mathrm{~s}$ in the MPPT, non-MPPT, and proposed methods, respectively. Figure $4 \mathrm{c}$ shows the output power of the wind turbine (all wind turbines have the same results). It shows that the power increases to its nominal value in the proposed method. The steady-state value of the frequency depends on the available reserved power since the reference power is limited to its MPPT 
value. To restore the frequency to its nominal value, the reserved power should be determined based on the worst case scenario for frequency drop. During a bigger variation in load, the frequency can be restored to its nominal value with a higher reserved power. The results of this scenario is summarized in Table 2; $f_{\mathrm{u}}, f_{\mathrm{o}}, f_{\mathrm{ss}}$, and $t_{\mathrm{s}}$ are frequency undershoot, frequency overshoot, steady-state frequency, and settling time, respectively (indices I and II indicate the scenario number).
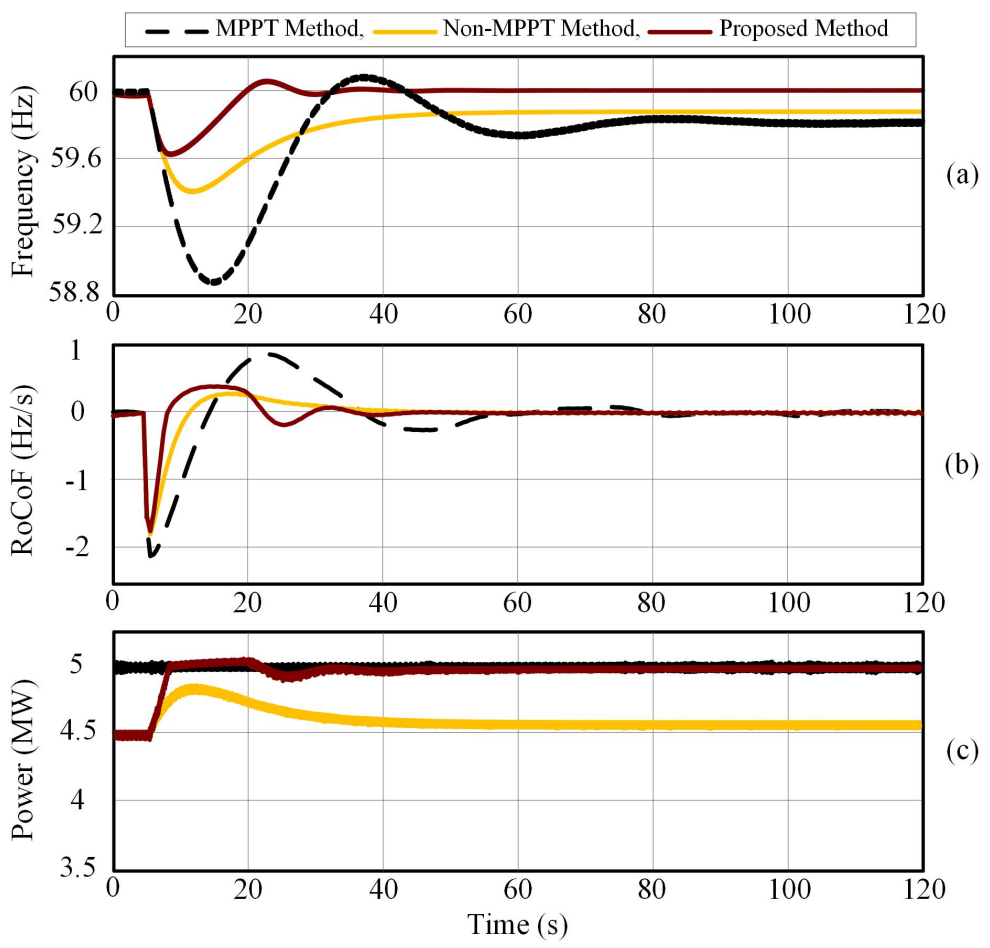

Figure 4. Dynamic response of the PMSG wind turbine subsequent to load connection (Scenario I): (a) frequency; (b) RoCoF; (c) wind turbine output power.

Table 2. Comparison of dynamic results for MPPT, non-MPPT, and proposed controllers.

\begin{tabular}{lcccccc}
\hline & $f_{\mathrm{u}, \mathbf{I}}(\mathbf{H z})$ & $f_{\mathrm{ss}, \mathbf{I}}(\mathbf{H z})$ & $\boldsymbol{t}_{\mathrm{s}, \mathrm{I}}(\mathbf{s})$ & $f_{\mathbf{o}, \mathrm{II}}(\mathbf{H z})$ & $f_{\mathrm{ss}, \mathrm{II}}(\mathbf{H z})$ & $\boldsymbol{t}_{\mathrm{s}, \mathrm{II}}(\mathbf{s})$ \\
\hline MPPT & 58.88 & 59.81 & 100 & 61.59 & 60.19 & 102 \\
Non-MPPT & 59.41 & 59.88 & 85 & 61.11 & 60.19 & 70 \\
Proposed & 59.63 & 60 & 62 & 60.36 & 60 & 57 \\
\hline
\end{tabular}

\subsection{Scenario II}

In Scenario II, both loads are connected to the system $\left(L_{1}+L_{2}\right)$ and then $L_{2}$ is disconnected at $t=5 \mathrm{~s}$. Figure 5 shows the simulation results for this scenario. Figure $5 \mathrm{a}$ shows that the frequency increases by disconnecting $L_{2}$. With MPPT and non-MPPT methods, the frequency rises to $61.59 \mathrm{~Hz}$ and $61.11 \mathrm{~Hz}$, respectively. In both methods, the steady-state value of the frequency is $60.19 \mathrm{~Hz}$. Using the proposed control method decreases the frequency overshoot to $60.36 \mathrm{~Hz}$ with a zero steady-state error. Figure 5a shows that the settling time in the proposed method reduces from $102 \mathrm{~s}$ (in the MPPT method) and $70 \mathrm{~s}$ (in the non-MPPT method) to $57 \mathrm{~s}$, which shows a $44 \%$ and $18 \%$ improvement, respectively. Figure $5 b$ shows a smaller $\mathrm{RoCoF}$ in the proposed method compared with the MPPT and non-MPPT methods. RoCoF reaches zero from peak in $9 \mathrm{~s}, 6.5 \mathrm{~s}$, and $3.5 \mathrm{~s}$ in the MPPT, non-MPPT, and proposed methods, respectively. Figure $5 \mathrm{c}$ shows the output power of the wind turbine (all of the wind turbines have the same results). It also shows that the reserved power is not used in this scenario since during a load reduction, the reference power decreases to provide frequency support. These results are summarized in Table 2. 

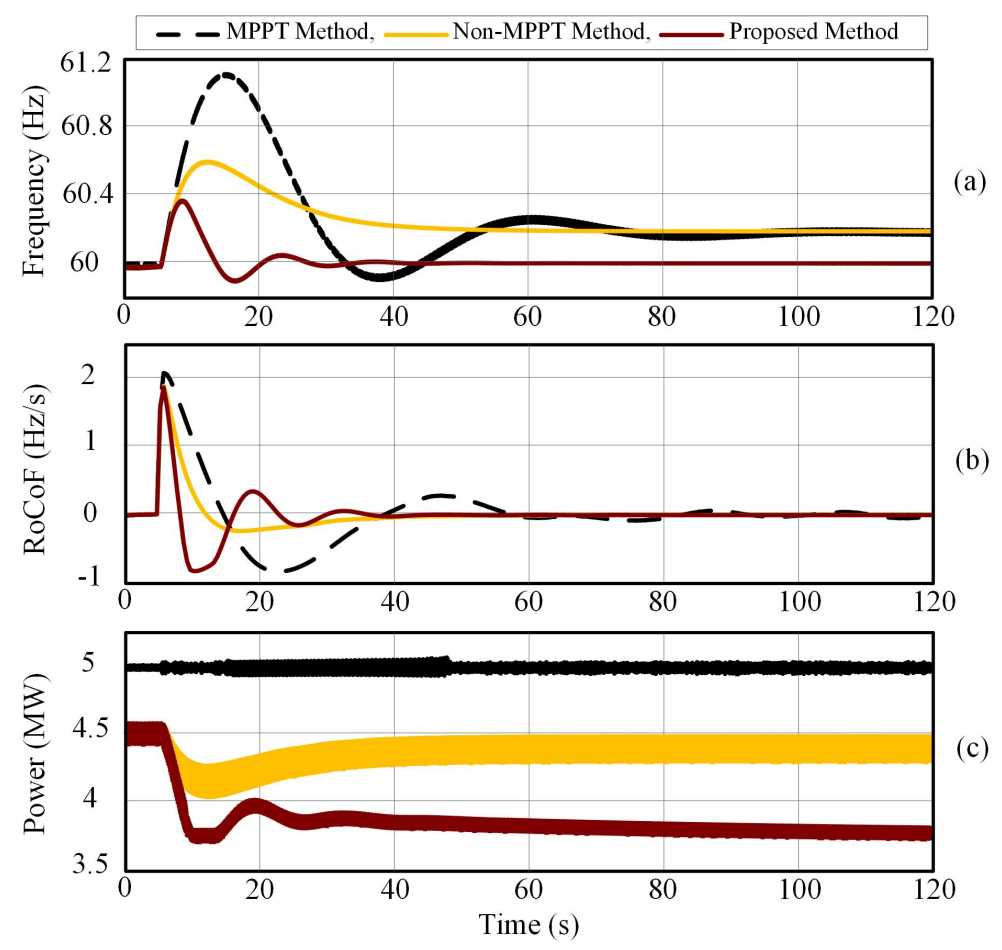

Figure 5. Dynamic response of the PMSG wind turbine subsequent to load reduction (Scenario II): (a) frequency; (b) RoCoF; (c) wind turbine output power.

\section{Conclusions}

In the power system with a high penetration of renewable energy resources such as wind turbines, the total inertia of the system decreases, which can exacerbate frequency transients. This letter proposes a new control method to improve the frequency response of a PMSG-based wind turbine connected to the grid. In the proposed method, the wind turbine works in the non-MPPT mode to generate more power during the load increase to regulate the frequency. Moreover, it uses a washout filter-based controller to restore the steady-state frequency to its nominal value with a faster dynamic compared with the conventional methods. The proposed method is purely a software-based control approach, which improves the frequency response of the system without any associated implementation cost. Simulation case studies in PSCAD/EMTDC validate the effectiveness of the proposed controller during load increase and reduction.

Author Contributions: In this paper, P.M.S. studied the literature review, proposed the control algorithm, and developed the simulation case studies under the supervision of A.M.-S. The paper has been written by P.M.S. and edited by A.M.-S. All authors have read and agreed to the published version of the manuscript.

Funding: This work is supported in part by Manitoba Hydro International and in part by National Science Foundation under award ECCS-1509895.

Conflicts of Interest: The authors declare no conflict of interest.

\section{References}

1. Primary Energy Production by Source. 2019. Available online: https://www.eia.gov/totalenergy/data/ annual/ (accessed on 13 September 2020).

2. Li, Y.; Xu, Z.; Wong, K.P. Advanced Control Strategies of PMSG-Based Wind Turbines for System Inertia Support. IEEE Trans. Power Syst. 2017, 32, 3027-3037. [CrossRef]

3. Xi, J.; Geng, H. Decoupling Control Scheme for VSG-WPPs to Participate in Grid Frequency Response. IEEE Trans. Ind. Appl. 2019, 55, 6368-6375. [CrossRef] 
4. Yazdanian, M.; Mehrizi-Sani, A. Washout Filter-Based Power Sharing. IEEE Trans. Smart Grid 2016, 7, 967-968. [CrossRef]

5. Hassouneh, M.A.; Lee, H.-C.; Abed, E.H. Washout filters in feedback control: Benefits, limitations and extensions. In Proceedings of the 2004 American Control Conference, Boston, MA, USA, 30 June-2 July 2004; Volume 5, pp. 3950-3955.

6. Govinda, C.V.; Udhay, S.V.; Rani, C.; Wang, Y.; Busawon, K. A Review on Various MPPT Techniques for Wind Energy Conversion System. In Proceedings of the International Conference on Computation of Power, Energy, Information and Communication (ICCPEIC), Chennai, India, 28-29 March 2018; pp. 310-326.

7. Kumar, S.S.; Jayanthi, K.; Kumar, N.S. Maximum power point tracking for a PMSG based variable speed wind energy conversion system using optimal torque control. In Proceedings of the International Conference on Advanced Communication Control and Computing Technologies (ICACCCT), Ramanathapuram, India, 25-27 May 2016; pp. 347-352.

8. Wei, C.; Zhang, Z.; Qiao, W.; Qu, L. An Adaptive Network-Based Reinforcement Learning Method for MPPT Control of PMSG Wind Energy Conversion Systems. IEEE Trans. Power Electron. 2016, 31, 7837-7848. [CrossRef]

9. Errami, Y.; Benchagra, M.; Hilal, M.; Maaroufi, M.; Ouassaid, M. Control strategy for PMSG wind farm based on MPPT and direct power control. In Proceedings of the International Conference on Multimedia Computing and Systems, Tangier, Morocco, 10-12 May 2012; pp. 1125-1130.

10. Clark, K.; Miller, N.W.; Sanchez-Gasca, J.J. Modeling of GE wind turbine-generators for grid studies. GE Energy 2010, 4, 0885-8950.

(C) 2020 by the authors. Licensee MDPI, Basel, Switzerland. This article is an open access article distributed under the terms and conditions of the Creative Commons Attribution (CC BY) license (http:/ / creativecommons.org/licenses/by/4.0/). 